\title{
Post-Extraction Ridge Preservation Using BioOss, Porcine Collagen Matrix and Immediate Dental Implant Placement: 18-Month follow-Up
}

\section{Cimara Fortes Ferreira ${ }^{1 *}$, Cleide Gisele Ribeiro², Geovana Gomes e Santos ${ }^{3}$, Adriana Araújo de Oliveira Paiva ${ }^{4}$, and Neuza Maria Souza Picorelli Assis ${ }^{5}$}

${ }^{1}$ Associate Professor, Director of Implant Dentistry, Department of Periodontics, University of Tennessee School of Dentistry, Memphis, TN, USA ${ }^{2}$ Professor, Hospital Maternidade Therezinha de Jesus-HMTJ/JF and Suprema-Faculdade Ciências Médicas e da Saúde, Juiz de Fora, Minas Gerais, Brazil ${ }^{3}$ Graduate student, Hospital Maternidade Therezinha de Jesus-HMTJ/JF and Suprema-Faculdade Ciências Médicas e da Saúde, Juiz de Fora, Minas Gerais, Brazil

${ }^{4}$ Master student in Dentistry, Federal University of Juiz de Fora, Minas Gerais, Brazil

${ }^{5}$ Associate Professor in Maxillofacial Surgery, Federal University of Juiz de Fora, Minas Gerais, Brazil

*Corresponding author: Cimara Fortes Ferreira, Associate Professor, Director of Implant Dentistry, Department of Periodontics, University of Tennessee School of Dentistry, Memphis, TN, USA, Tel: (901) 448-4494; E-mail: cimarafortes@hotmail.com

Received: 22 Jun, 2020 | Accepted: 07 Jul, 2020 | Published: 14 Jul, 2020

Citation: Ferreira CF, Ribeiro CG, e Santos GG, de Oliveira Paiva AA, Assis NMSP (2020) Post-Extraction Ridge Preservation Using BioOss, Porcine Collagen Matrix and Immediate Dental Implant Placement: 18-Month follow Up. Int J Dent Oral Health 6(5): dx.doi.org/10.16966/23787090.330

Copyright: (c) 2020 Ferreira CF, et al. This is an open-access article distributed under the terms of the Creative Commons Attribution License, which permits unrestricted use, distribution, and reproduction in any medium, provided the original author and source are credited.

\section{Aim}

Background: Immediate implant placement is a popular treatment modality among dental surgeons for the treatment of tooth loss. However, due to the higher esthetic risks for this procedure, some strategies have been proposed to reduce this risk. The present case report shows the substitution of a maxillary central incisor with root resorption by an immediate implant and placement of biomaterials. Case description: A 34-year-old female reported avulsion of \#9 when she was 13 years old. A Computerized tomography scan showed substitution root resorption on \#9. An immediate implant was planned for that site. The space between the implant surface and the labial osseous wall was filled with Deproteinized Bovine Bone (DBB). Next, the coronal aspect of the socket was sealed with collagen matrix. At second stage surgery, a provisional screw-retained crown was fabricated and delivered. The definitive crown was delivered 5 months later.

Conclusion: The esthetic results at the immediate and the 18-month follow-up were very pleasing, showing maintenance of the peri-implant bone and gingival-like tissues. Clinical significance: Immediate implant placement in the anterior maxilla with adjunct bone grafting can be a successful procedure.

Keywords: Clinical technique; Case report; Esthetic zone; Ridge preservation; Immediate implant placement; Bone chips; Collagen membrane

\section{Background}

Dental implant placement can be classified in relation to the timing after tooth extraction: [1] Type 1 or immediate placement, implant placed in extraction sockets; type 2 or early, implant placed after gingiva-like tissue coverage of the socket; type 3 or early with partial bone healing, after significant clinical and/or radiographic bone fill of the socket; and, type 4 or late, implant placed in a repaired extraction site [1]. Interest has increased in the treatment outcomes of type 1 and type 2 implant placement protocols, especially in the anterior maxilla [2].

Immediate implant placement gained acceptance among clinicians and patients, due to its shorter treatment time, fewer surgical procedures, and similar survival rate when compared to delayed placement [3]. However, extraction and replacement of single dental implants in the esthetic zone remains a challenging procedure. Alveolar bone resorption after exodontia causes dimensional changes to the alveolar ridge that affect the buccal aspect of the socket with greater intensity [4,5]. Flapless approach is recommended to preserve the blood supply to the facial bone and to favor soft tissue healing as well as increase patient comfort when performing immediate implant placement [6]. However, a flapless approach can result in an unesthetic restoration if peri-implant mucosal recession is present [2]. Alternatively, simultaneous use of barrier membranes [7], bone replacement grafts [4], and/or soft tissue grafts [8] have been reported to counter balance the physiologic bone resorption and to limit bone volume loss.

Gingival grafts have been used to close the alveolar socket and enhance the soft tissues prior [9] or simultaneous to immediate implant placement $[10,11]$ Gingival grafting at the time of immediate implant placement, in addition to socket grafting using a bovinederived bone substitute, may improve soft tissue healing six weeks post-exodontia [12]. 
The choice between epithelial connective tissue grafts $v s$. porcine collagen matrix may depend on several variables, such as tissue phenotype, size of the defect, clinician's expertise, and the patient's preference. The use of porcine collagen matrix as an adjunct to ridge preservation procedures using Deproteinized Bovine Bone (DBB) may be an acceptable alternative to epithelial connective tissue graft, reducing surgical time and patient morbidity [13].

Thus, the objective of the present clinical case was to compare the contours of the peri-implant soft tissue immediately and at the 18-month follow-up of immediate dental implant placement combined with ridge preservation using a DBB bone chips and porcine collagen matrix.

\section{Technique}

Following the initial screening, clinical and tomographic comprehensive exams were undertaken by the surgical and restorative providers. The patient had acceptable contours of the soft tissues of tooth \#9, however, the crown showed a dark shade (Figure 1). Clinical exam showed acceptable ridge dimensions for implant placement, which had to be confirmed with Cone Beam Computerized Tomography scan (CBCT) (Figure 2). A CBCT showed extensive root resorption for \#9, however it still showed sufficient buccal, palatal and apical bony tissue, enabling immediate implant placement (Figure 3). All surgical procedures were conducted under local an aesthesia. A surgical guide was prepared and the surgery schedule. Five-hundred milligrams of amoxicillin was prescribed every 8 hours for 7 days, starting 1 day prior to the scheduled surgery. The Patients rinsed with $0.2 \%$ chlorhexidine solution for 2 minutes prior to anesthesia. A minimally traumatic flapless extraction was performed. A bone level implant (3,3 × 12mm; Straumann AG, Basel, Switzerland) was placed following the manufacturer's recommendations. During the implant site osteotomy care was taken to promote ideal implant primary stability placement for a future screw-retained crown. In addition, care was taken to avoid damage to the buccal socket wall. The palatal and apical bone was engaged by the implant in a correct restoratively driven 3-dimensional position. The implant was positioned in the cingulum aspect of the extracted tooth (Figure 4). The peri-implant soft tissues were maintained post-extraction of \#9 (Figure 5).

The gap between the implant and the inner aspect of the buccal socket wall was filled with DBB particles (Bio-Oss ${ }^{\oplus}$, Geistlich Pharma AG, Wolhusen, Switzerland) (Figure 6). Next, the coronal margins of the soft tissues were de-epithelized and the graft particles were covered with a porcine collagen matrix (Mucograft Seal ${ }^{\circ}$, Geistlich Pharma AG, Wolhusen, Switzerland) (Figure 7). The flap was repositioned to obtain tension-free closure and an " $\mathrm{x}$ " suture was made with a 4-0 cromic gut thread to secure the collagen matrix placed to cover the particular xenograft (Figure 8). Post-operative instructions included chlorhexidine rinses twice daily, for a period of 2 weeks and antibiotic therapy with amoxicillin for 1 week. Ibuprofen $400 \mathrm{mg}$ was prescribed for pain control. A provisional bridge was fabricated and cemented to the adjacent teeth post-operatively (Figure 9).

Three months post-operatively, a screw-retained interim restoration was fabricated using stock provisional teeth (Figure 10). Next, a final implant transfer open-tray impression was made by means of polyether material. The open tray impression coping was customized with flow composite resin to transfer the position of the soft tissues to the master cast (Figure 11). The patient was satisfied with the provisionalization of \#9i (Figure 12).

The patient used the provisional for 5 months when she returned to the office for treatment planning the final restorations. After removal of the provisional for \#9i, the peri-implant tissue architecture was clinically healthy and with sufficient volume (Figure 13) for an esthetically acceptable result. After various treatment options were presented to the patient, she chose an all-ceramic zirconia crown for $\# 8$, due to its dark shade. Individualized CAD/CAM zirconia abutment (Lava Plus High Translucency Zirconia Build up for two-piece abutment, 3M ESPE, St. Paul, MN, USA) was used as the framework (Figure 14) and then directly veneered with a feldspathic porcelain (VitablocsTrilux forte, VITA Zahnfabrik, Bad Sackingen, Germany). The zirconia was not veneered in the emergence profile area to optimize biocompatibility. The veneered abutment was extra orally cemented on a titanium base (Variobase, Straumann. AG, Basel, Switzerland) using a composite resin cement (Panavia $21^{\circ}$, Kuraray Medical Inc., Osaka, Japan). The structures were then torqued to the correponding implant following the manufacturer's recommendations. The patient was satisfied with the final esthetic result. The \#9i showed very similar peri-implant tissue architecture when compared to the periodontal tissues for \#8 (Figures 15 and 16).

At the 18-month follow-up visit, there were no prosthetic complications and the peri-implant tissues were stable. Patient presented acceptable oral hygiene and no chief complaints. She was very satisfied with the esthetics. An adequate emergence profile and dimensions of papillae were obtained (Figure 17).

\section{Discussion}

After tooth loss, the edentulous alveolar ridge volume decreases, especially on the buccal aspect, resulting in a palatal and lingual shift of the residual crest [14-17]. Clinicians must be aware of this physiological process as it may compromise future implant placement or conventional prosthetic restorations for rehabilitation of the site [18]. This case report shows a successful esthetic result with the socket seal technique. In addition, there was minimal shrinkage of the soft and hard tissues in both horizontal and vertical dimensions.

Although many studies have investigated healing and remodeling in the buccal socket wall after immediate implant placement, the reported results have been characterized by their heterogeneity, such as lack of standardization in the preclinical methods, of surgical protocols, implant systems and probably the inherent variability in the biological wound-healing process of the socket [19]. Buccal bone height reduction of approximately $2.2 \mathrm{~mm}$ has been reported after a 3-month healing [20], while a similar study showed $0.8 \mathrm{~mm} \mathrm{[21].}$ Similar results have been reported previously in cases of immediate and early implant placements [22-24]. Implant diameter and implant position, 7 the thickness of the buccal bone plate [25], flapless versus flapped surgical intervention [26], or the use of biomaterials filling the gap [27] are known factors that may influence the vertical resorption of the socket's buccal bony wall. Nevertheless, some studies have shown that immediate implant placement does not prevent post-extraction bone remodeling $[20,28]$. Single-tooth implants placed in the anterior maxilla with either an immediate or early placement protocol showed $100 \%$ survival rate for both groups at the 1-year follow-up visit [29].

DBB grafts have shown low resorption rate, being appropriate for ridge preservation procedures $[5,12,30]$. The use of DBB (BioOss ${ }^{\oplus}$, Geistlich Pharma AG, Wolhusen, Switzerland) bone chips along with a membrane placed with an immediate transmucosal implants may offer an advantage in areas with high esthetic demands [28,31]. This case report shows a slow-rate resorption DBB graft (BioOss ${ }^{\oplus}$, Geistlich Pharma AG, Wolhusen, Switzerland) with a resorbable porcine collagen matrix (Bio-Gide ${ }^{\oplus}$, Geistlich Pharma AG, Wolhusen, Switzerland) for guided bone regeneration, which proved to be effective in maintaining the esthetic results. 


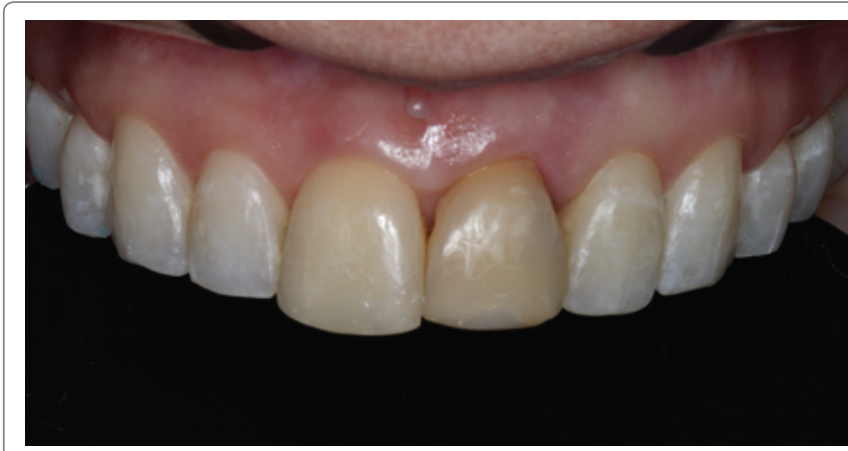

Figure 1: Frontal view of the maxillary teeth. Note presence of dark shade for teeth \#8 \& 9.

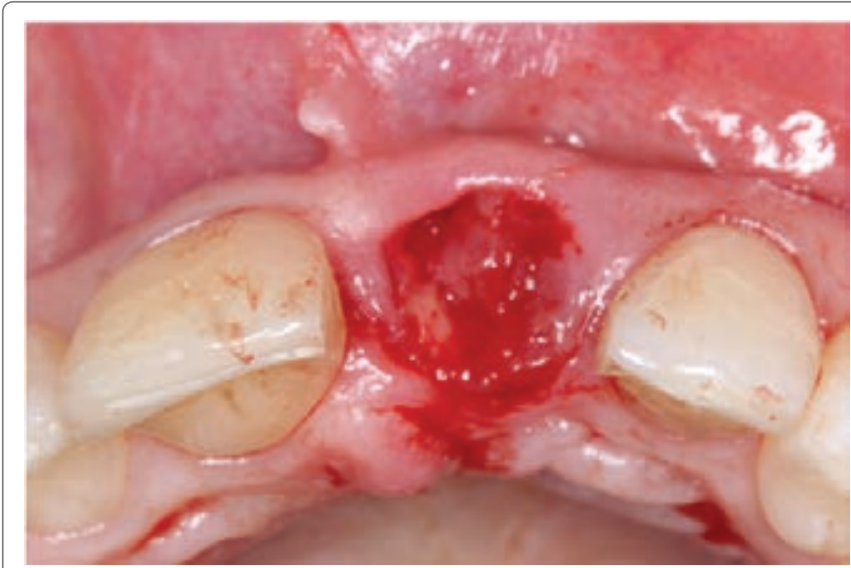

Figure 2: Occlusal view post-extraction of \#9. Note present of acceptable ridge width for placement of an implant. Soft tissue contours were maintained.

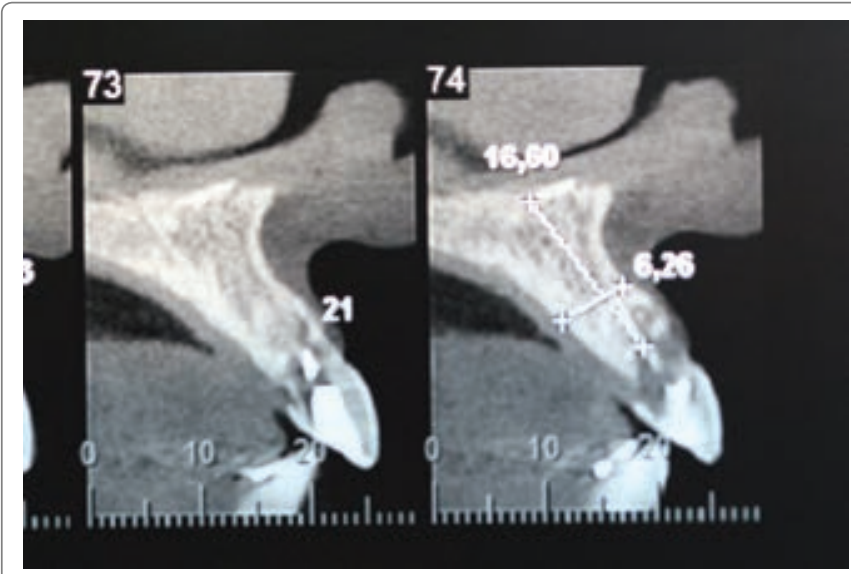

Figure 3: $C B C T$ scan showing extensive root resorption for \#9, however there is sufficient buccal, palatal and apical bony tissue, enabling immediate implant placement.

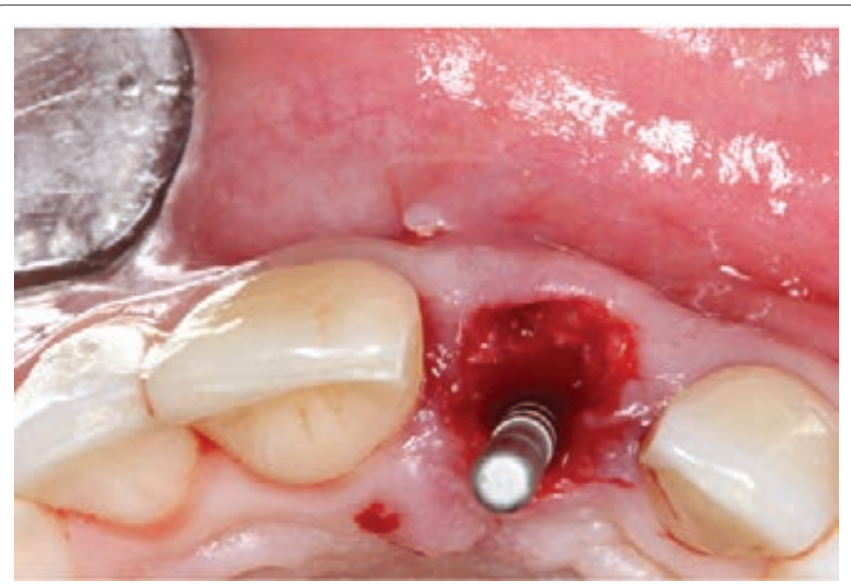

Figure 4: Occlusal view of the implant placed for site \#9. Note palatal approach of the implant on the anatomical cingulum of the extracted tooth in order to facilitate the prothetic rehabilitation.

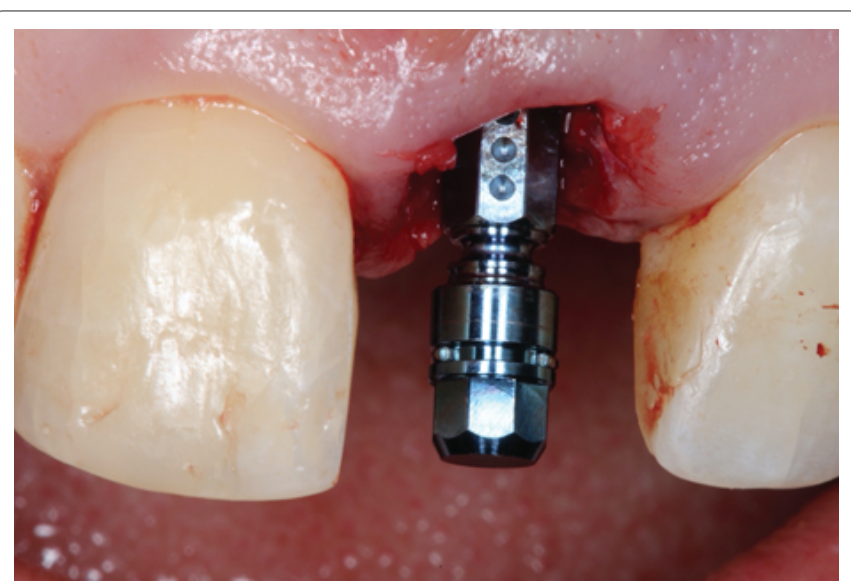

Figure 5: Frontal view of the immediately placed implant for \#9 sites. Note maintenance of the architecture of the peri-implant soft tissues.

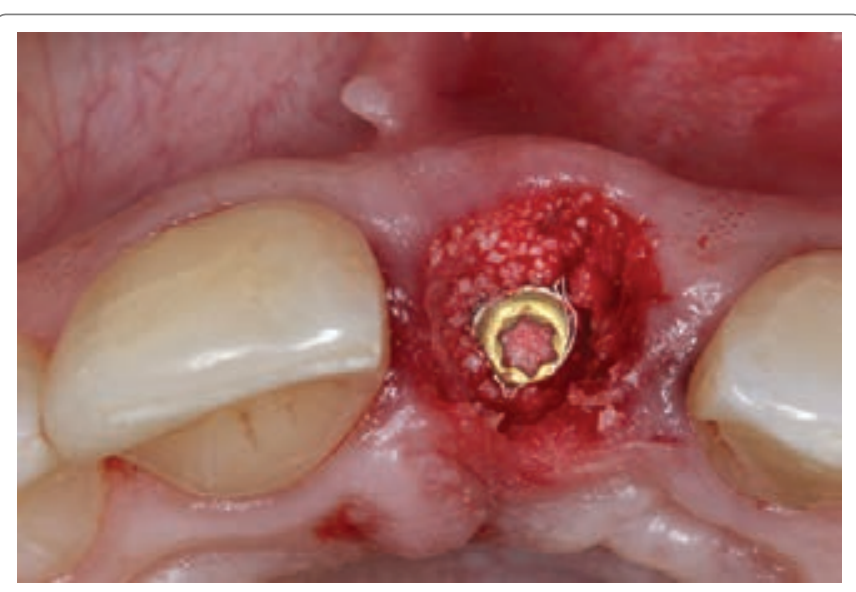

Figure 6: The gap between the implant and the inner aspect of the buccal socket wall was filled with DBB particles. 


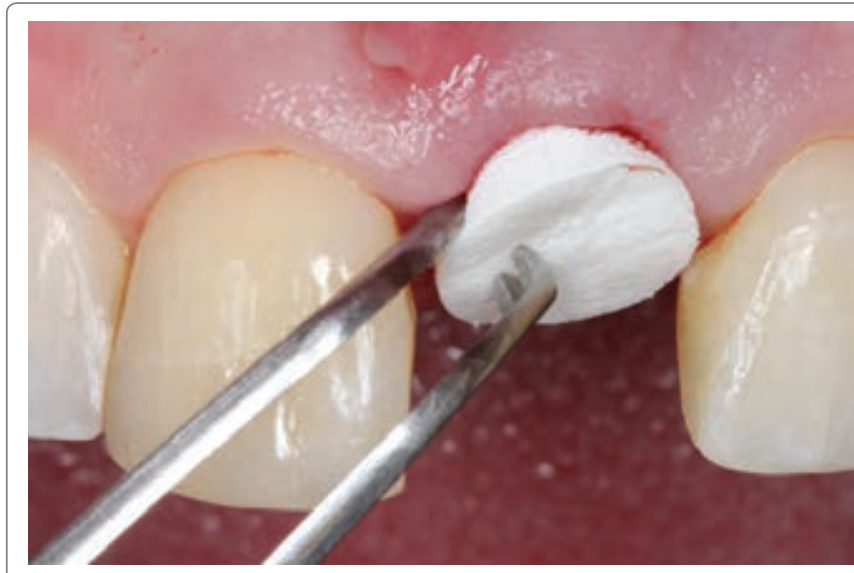

Figure 7: Aporcine collagen matrix was placed to cover the coronal aspect of the socket.

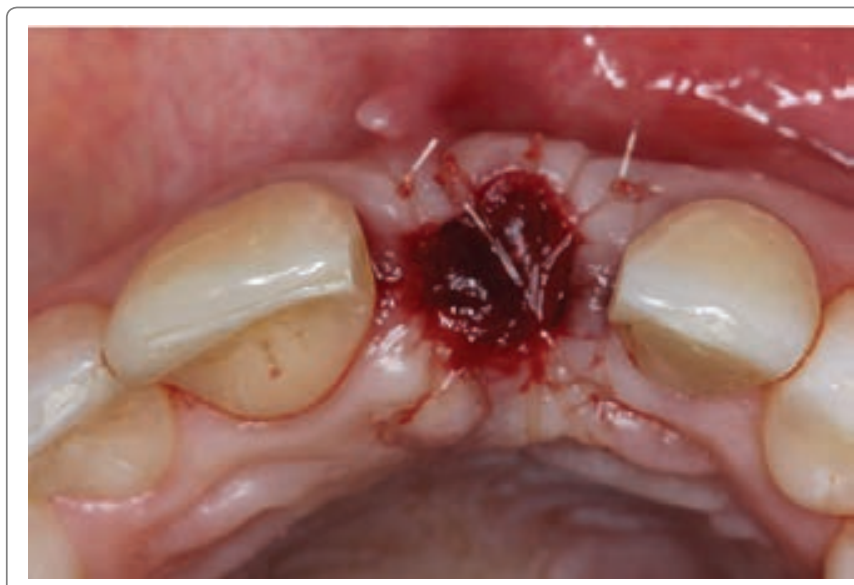

Figure 8: An " $x$ " suture was made with a 4-0 cromic gut thread to secure the collagen matrix placed to cover the particular xenograft.

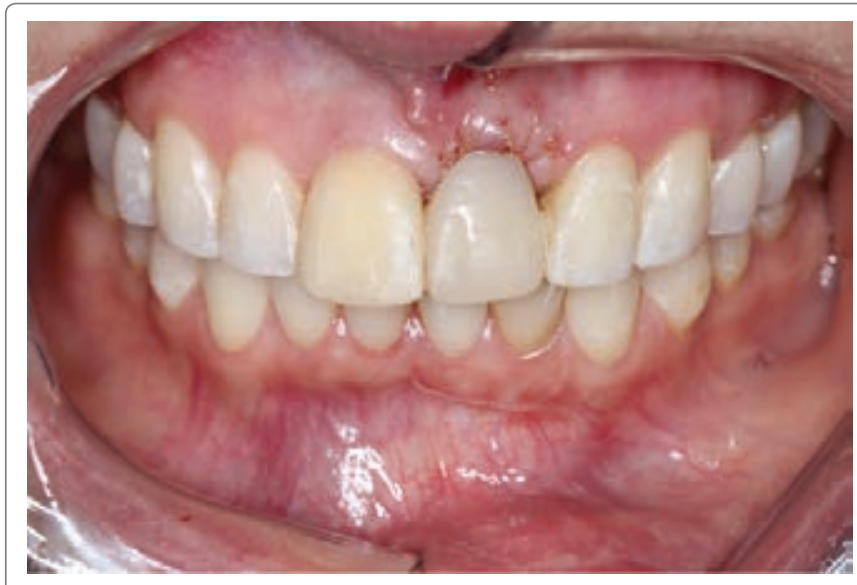

Figure 9: Immediate post-operative frontal view of the maxillary teeth. A provisional bridge was fabricated and cemented to the adjacent teeth post-operatively.

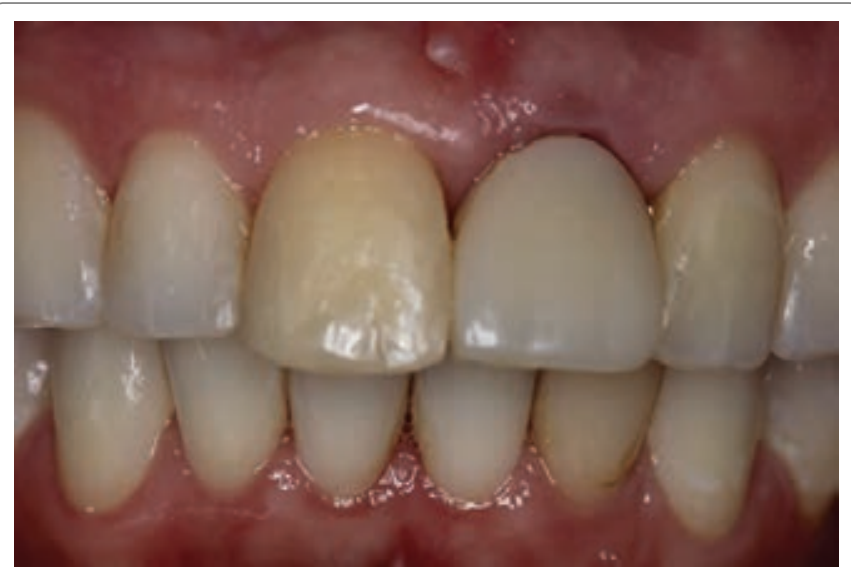

Figure 10: Frontal view of \#9i. Three month post-operative frontal view of \#9. Note maintenance of the peri-implant soft tissue architecture.

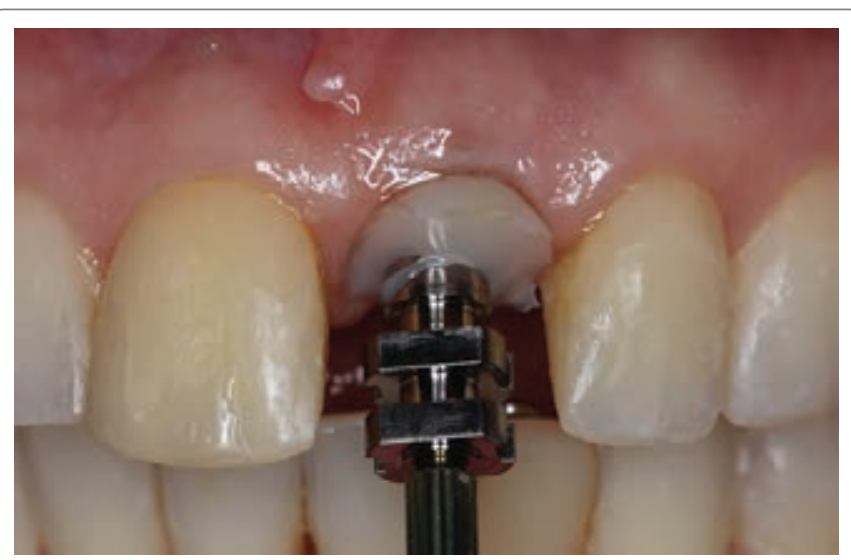

Figure 11: Frontal view of \#9i. The open tray impression coping was customized with flow composite resin to transfer the position of the soft tissues to the master cast.

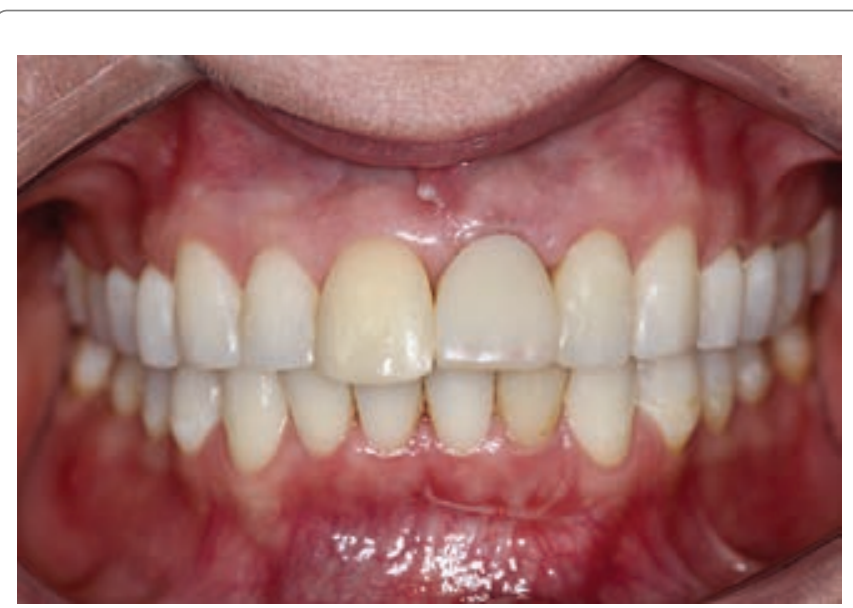

Figure 12: Esthetic result after provisionalization of \#9i. 


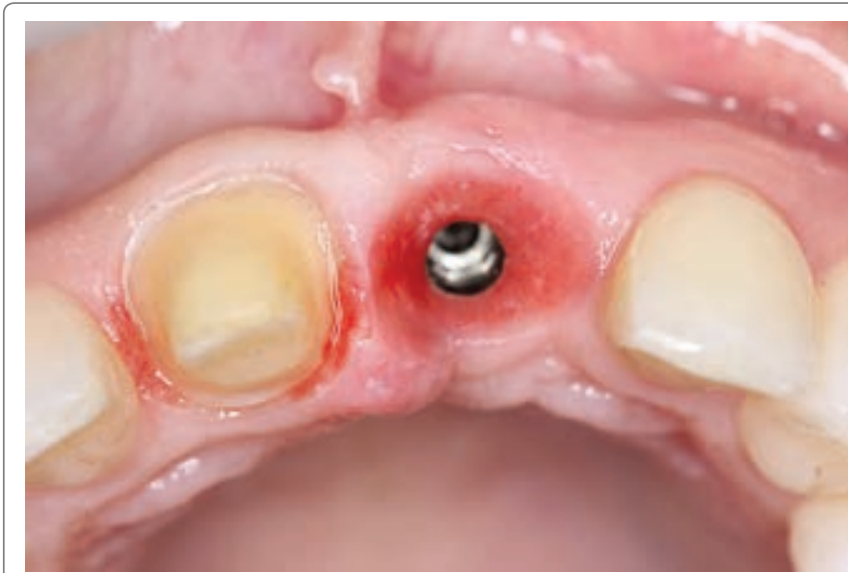

Figure 13: 5-month post provisionalization. After removal of the provisional for \#9i, note the peri-implant tissue architecture is clinically healthy and with sufficient buccal-palatal volume for an esthetically pleasing restoration.

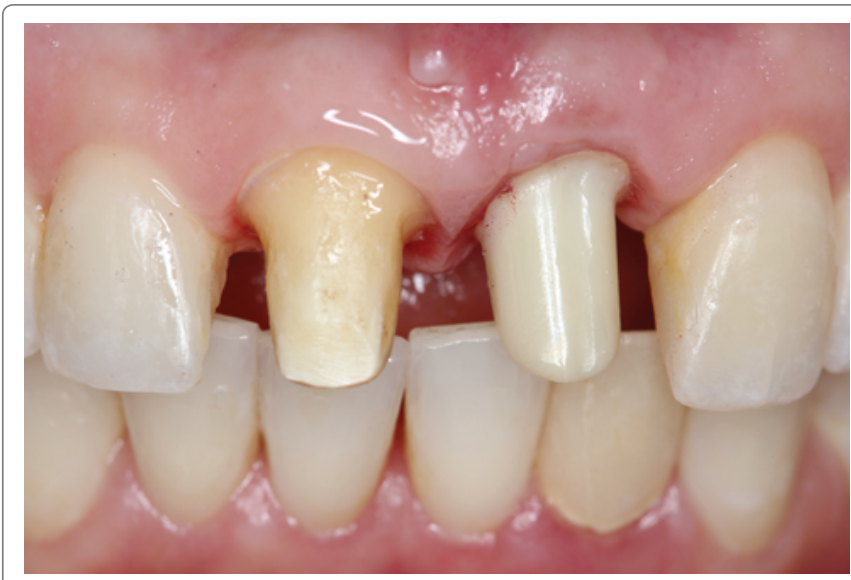

Figure 14: Frontal view of the anterior maxilla. Note that \#9i received a CAD/CAM zirconia abutment. Note the presence of mesial and distal papilla-like peri-implant tissues for \#9i.

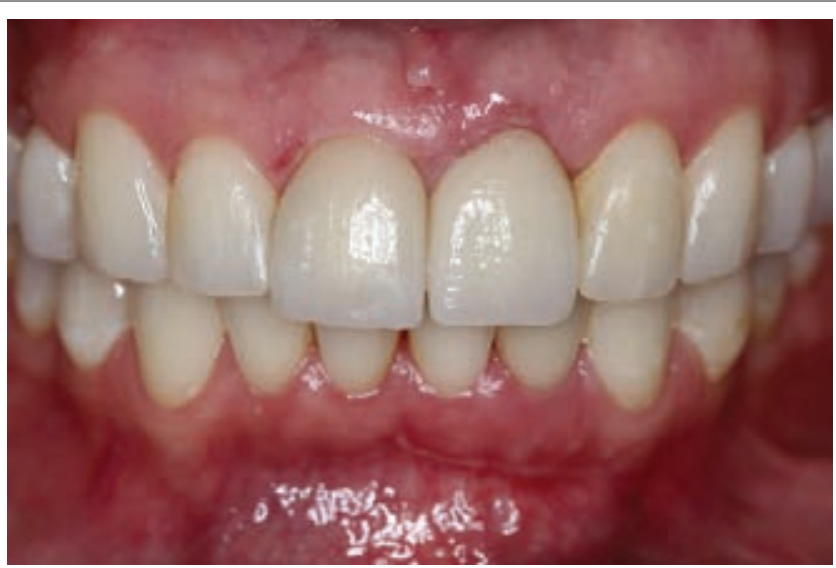

Figure 15: Frontal view of the maxillary teeth. Note very similar periimplant tissue architecture for \#9i when compared to the periodontal tissues for \#8.

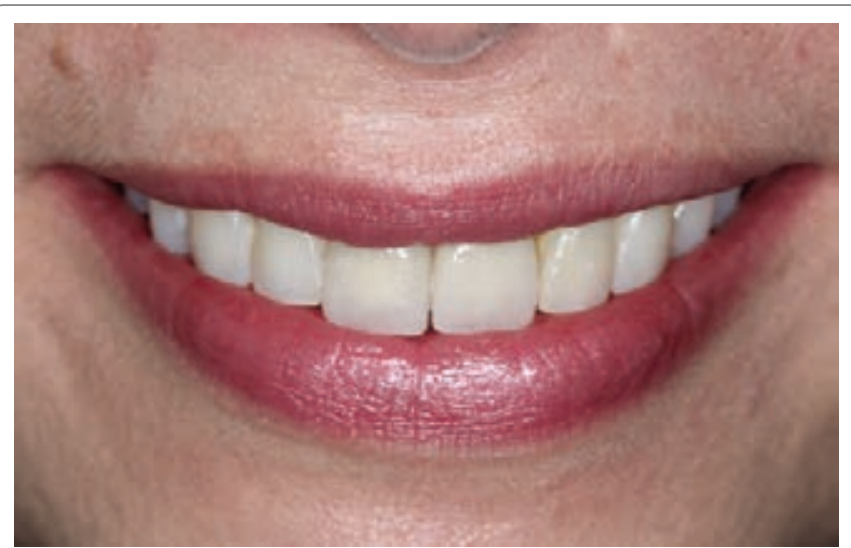

Figure 16: Frontal view of the patient's smile at the 18-month followup. Note the homogenous esthetics obtained by the directly veneered feldspathic porcelain crown for \#8 and the veneered abutment for \#9i.

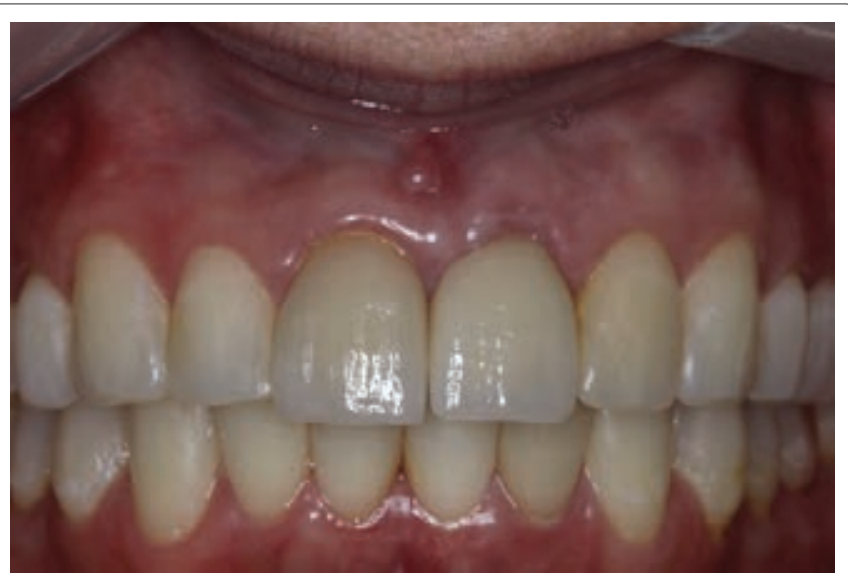

Figure 17: Frontal view of the 18-month follow-up visit. Note an adequate emergence profile and dimensions of papillae.

Furthermore, the literature suggests the use of barrier membranes and/or soft tissue grafts to mitigate ridge reduction; however, these data are inconclusive $[32,5]$. Ridge preservation using Free Gingival Punch Graft (FGPF) showed the lowest volumetric changes with or without bone grafting [33]. However, a recent consensus statement was inconclusive when comparing the use or not of soft tissue graft to ridge preservation procedures (Wang, 2012) which increases the morbidity of the procedure. A disadvantage of the FGPF is scarring of the buccal aspect of the ridge due to its incomplete healing.

Other factors appear to influence the resorption rate of the buccal aspect of the ridge, such as the type of prosthetic connection. External hex implant connections are associated with greater bone loss when compared to internal connection implants; that is, conical and platform switched connections [3437]. Conical connection implants offer a higher resistance to microbial microleakage [38-40]. The Morse Taper interface, which has a conical internal connection, shows increased contact area, reduced micro movement and a tighter fit with the abutment (Sans et al, 2017; Agustin-Panadero et al, 2019). The implant used in 
the present case report was an internal connection with platform switching.

\section{Conclusion}

A combination of technique used and quality of the materials is what may increase the functional and esthetic predictability of restorations. Porcine collagen matrix may simplify the treatment protocol, hence being suitable for sealing post extraction sockets grafted with DBB graft. The authors suggests the use of the immediate implant placement with grafting and socket seal as an alternative to ridge preservation procedures that require harvesting a connective tissue graft. The association of porcine collagen matrix, DBB graft, internal connection implant and platform switching may be considered a successful approach for immediate implant placement in the anterior maxilla. Furthermore, randomized controlled clinical trials are needed to confirm our clinical outcome.

\section{Acknowledgements}

This case report was not funded by any institution. This case report was approved by the patient for the images to be published.

\section{References}

1. Hammerle CH, Chen ST, Wilson TG Jr (2004) Consensus statements and recommended clinical procedures regarding the placement of implants in extraction sockets. Int J Oral Maxillofac Implants 19: 2628.

2. Chen ST, Buser D (2014) Esthetic outcomes following immediate and early implant placement in the anterior maxilla-a systematic review. Int J Oral Maxillofac Implants 29: 186-215.

3. Lang NP, Pun L, Lau KY, Li KY, Wong MC (2012) A systematic review on survival and success rates of implants placed immediately into fresh extraction sockets after at least 1 year. Clin Oral Implants Res 23: 39-66.

4. Araujo MG, Lindhe J (2005) Dimensional ridge alterations following tooth extraction. An experimental study in the dog. J Clin Periodontol 32: $212-218$

5. Fickl S, Zuhr O, Wachtel H, Stappert CFJ, Stein JM, et al. (2008) Dimensional changes of the alveolar ridge contour after different socket preservation techniques. J Clin Periodontol 35: 906-913.

6. Mazzocco F, Jimenez D, Barallat L, Paniz G, Del Fabbro M, et al. (2017) Bone volume changes after immediate implant placement with or without flap elevation. Clin Oral Implants Res 28: 495-501.

7. Caneva M, Salata LA, de Souza SS, Bressan E, Botticelli D, et al. (2010) Hard tissue formation adjacent to implants of various size and configuration immediately placed into extraction sockets: an experimental study in dogs. Clin Oral Implants Res 21: 885-890.

8. Grunder U (2011) Crestal ridge width changes when placing implants at the time of tooth extraction with and without soft tissue augmentation after a healing period of 6 months: report of 24 consecutive cases. Int J Periodontics Restorative Dent 31: 9-17.

9. Oghli AA, Steveling $H$ (2010) Ridge preservation following tooth extraction: a comparison between atraumatic extraction and socket seal surgery. Quintessence Int 41: 605-609.

10. Stimmelmayr M, Allen EP, Reichert TE, Iglhaut G (2010) Use of a combination epithelized-subepithelial connective tissue graft for closure and soft tissue augmentation of an extraction site following ridge preservation or implant placement: description of a technique. Int J Periodontics Restorative Dent 30: 375-381.
11. Landsberg CJ, Bichacho N (1994) A modified surgical/prosthetic approach for optimal single implant supported crown. Part I-The socket seal surgery. Pract Periodontics Aesthet Dent 6: 11-17; quiz 19.

12. Jung RE, Philipp A, Annen BM, Signorelli L, Thoma DS, et al. (2013) Radiographic evaluation of different techniques for ridge preservation after tooth extraction: a randomized controlled clinical trial. J Clin Periodontol 40: 90-98.

13. Thoma DS, Sancho-Puchades M, Ettlin DA, Hammerle CH, Jung RE (2012) Impact of a collagen matrix on early healing, aesthetics and patient morbidity in oral mucosal wounds-a randomized study in humans. J Clin Periodontol 39: 157-165.

14. Pietrokovski J, Massler M (1967) Alveolar ridge resorption following tooth extraction. J Prosthet Dent 17: 21-27.

15. Younis L, Taher A, Abu-Hassan MI, Tin O (2009) Evaluation of bone healing following immediate and delayed dental implant placement. J Contemp Dent Pract 10: 35-42.

16. Barone A, Ricci M, Calvo-Guirado JL, Covani U (2011) Bone remodelling after regenerative procedures around implants placed in fresh extraction sockets: an experimental study in Beagle dogs. Clin Oral Implants Res 22: 1131-1137.

17. Schropp L, Wenzel A, Kostopoulos L, Karring T (2003) Bone healing and soft tissue contour changes following single-tooth extraction: a clinical and radiographic 12-month prospective study. Int J Periodontics Restorative Dent 23: 313-323.

18. Abrams $L$ (1980) Augmentation of the deformed residual edentulous ridge for fixed prosthesis. Compend Contin Educ Gen Dent 1: 205-213.

19. Vignoletti F, Sanz M (2014) Immediate implants at fresh extraction sockets: from myth to reality. Periodontol 2000 66: 132-152.

20. Araujo MG, Sukekava F, Wennstrom JL, Lindhe J (2005) Ridge alterations following implant placement in fresh extraction sockets: an experimental study in the dog. J Clin Periodontol 32: 645-652.

21. Vignoletti $F$, de Sanctis $M$, Berglundh $T$, Abrahamsson I, Sanz M (2009) Early healing of implants placed into fresh extraction sockets: an experimental study in the beagle dog. II: ridge alterations. J Clin Periodontol 36: 688-697.

22. Arora H, Khzam N, Roberts D, Bruce WL, Ivanovski S (2017) Immediate implant placement and restoration in the anterior maxilla: Tissue dimensional changes after 2-5 year follow up. Clin Implant Dent Relat Res 19: 694-702.

23. Noelken R, Neffe BA, Kunkel M, Wagner W (2014) Maintenance of marginal bone support and soft tissue esthetics at immediately provisionalized OsseoSpeed implants placed into extraction sites: 2-year results. Clin Oral Implants Res 25: 214-220.

24. Slagter KW, Meijer HJ, Bakker NA, Vissink A, Raghoebar GM (2016) Immediate Single-Tooth Implant Placement in Bony Defects in the Esthetic Zone: A 1-Year Randomized Controlled Trial. J Periodontol 87: 619-629.

25. Araujo MG, Wennstrom JL, Lindhe J (2006) Modeling of the buccal and lingual bone walls of fresh extraction sites following implant installation. Clin Oral Implants Res 17: 606-614.

26. Blanco J, Nunez V, Aracil L, Munoz F, Ramos I (2008) Ridge alterations following immediate implant placement in the dog: flap versus flapless surgery. J Clin Periodontol 35: 640-648.

27. Araujo MG, Linder E, Lindhe J (2011) Bio-Oss collagen in the buccal gap at immediate implants: a 6-month study in the dog. Clin Oral Implants Res 22: 1-8. 
28. Chen ST, Darby IB, Reynolds EC, Clement JG (2009) Immediate implant placement postextraction without flap elevation. J Periodontol 80: 163-172.

29. Arora H, Ivanovski S (2018) Immediate and early implant placement in single-tooth gaps in the anterior maxilla: A prospective study on ridge dimensional, clinical, and aesthetic changes. Clin Oral Implants Res.

30. Chen Z, Li J, Wang HL, Yu H (2019) Initial Bone Volume Changes After Immediate Implant Placement Associated with Filling the Gap Using Bovine Bone in Molar Sites. Int J Oral Maxillofac Implants 34: 521528.

31. Cornelini R, Cangini F, Martuscelli G, Wennstrom J (2004) Deproteinized bovine bone and biodegradable barrier membranes to support healing following immediate placement of transmucosal implants: a short-term controlled clinical trial. Int J Periodontics Restorative Dent 24: 555-563.

32. Vignoletti F, Matesanz P, Rodrigo D, Figuero E, Martin C, et al. (2012) Surgical protocols for ridge preservation after tooth extraction. A systematic review. Clin Oral Implants Res 23: 22-38.

33. Thalmair T, Fickl S, Schneider D, Hinze M, Wachtel H (2013) Dimensional alterations of extraction sites after different alveolar ridge preservation techniques-a volumetric study. J Clin Periodontol 40: 721-727.

34. Thoma DS, Muhlemann S, Jung RE (2014) Critical soft-tissue dimensions with dental implants and treatment concepts. Periodontol 2000 66: 106-118.
35. Cochran DL, Bosshardt DD, Grize L, Higginbottom FL, Jones AA, et al. (2009) Bone response to loaded implants with non-matching implant-abutment diameters in the canine mandible. J Periodontol 80: 609-617.

36. Penarrocha-Diago MA, Flichy-Fernandez AJ, Alonso-Gonzalez R, Penarrocha-Oltra D, Balaguer-Martinez J, et al. (2013) Influence of implant neck design and implant-abutment connection type on peri-implant health. Radiological study. Clin Oral Implants Res 24 $1192-1200$

37. Messias A, Rocha S, Wagner W, Wiltfang J, Moergel M, et al. (2019) Peri-implant marginal bone loss reduction with platform-switching components: 5-Year post-loading results of an equivalence randomized clinical trial. J Clin Periodontol 46: 678-687.

38. Aizcorbe-Vicente J, Penarrocha-Oltra D, Canullo L, Soto-Penaloza D, Penarrocha-Diago M (2020) Influence of Facial Bone Thickness After Implant Placement into the Healed Ridges on the Remodeled Facial Bone and Considering Soft Tissue Recession: A Systematic Review. Int J Oral Maxillofac Implants 35: 107-119.

39. Verdugo CL, Nunez GJ, Avila AA, Martin CLS (2014) Microleakage of the prosthetic abutment/implant interface with internal and external connection: in vitro study. Clin Oral Implants Res 25: 10781083.

40. Canullo L, Penarrocha-Oltra D, Soldini C, Mazzocco F, Penarrocha M, et al. (2015) Microbiological assessment of the implant-abutment interface in different connections: cross-sectional study after 5 years of functional loading. Clin Oral Implants Res 26: 426-434. 